BASIC RESEARCH

\title{
Distinct yet complementary mechanisms of heparin and glycoprotein Ilb/llla inhibitors on platelet activation and aggregation: implications for restenosis during percutaneous coronary intervention
}

\author{
J R S Day, I S Malik, A Weerasinghe, M Poullis, I Nadra, D O Haskard, K M Taylor, R C Landis
}

Heart 2004;90:794-799. doi: 10.1136/hrt.2003.017749

See end of article for authors' affiliations

Correspondence to: Mr J R S Day, British Heart Foundation Cardiovascular Medicine and Cardiac Surgery Unit, National Heart and Lung Institute, Imperial College School of Medicine, Hammersmith Hospital, 'Du Cane road, London W12 ONN, UK; i.day@imperial.ac.uk

Accepted

13 November 2003

\begin{abstract}
Objective: To study the effect of unfractionated heparin (UFH) versus low molecular weight heparin (LMWH) in combination with glycoprotein (Gp) Ilb/Illa blockers on platelet activation and aggregation. Methods: Washed platelets were stimulated with thrombin in the presence or absence of UFH (monoparin), LMWH (enoxaparin), and a Gp Ilb/llla blocker (abciximab, eptifibatide, or tirofiban).

Results: Although Gp Ilb/Illa antagonists blocked the final common pathway of thrombin induced platelet aggregation, UFH and LMWH were better at blocking upstream platelet activation. UFH was significantly more effective than $\mathrm{LMWH}$ at inhibiting $\mathrm{P}$ selectin expression $(p=0.001)$ and platelet derived growth factor release from thrombin activated platelets ( $p=0.012$ ).

Conclusions: UFH and LMWH exert complementary effects to Gp llb/llla blockers by inhibiting afferent pathways of platelet activation. Coadministration of heparin with Gp Ilb/Illa blockers provides improved protection against persistent platelet activation, thereby improving outcome after percutaneous coronary intervention. Judging from these data, UFH may be more effective in this regard than $L M W H$, at least in vitro. The use of LMWH in preference to UFH during percutaneous coronary intervention, although initially attractive, may inadequately protect against platelet activation despite the presence of $\mathrm{Gp}$ Illb/llla blockers.
\end{abstract}

$\mathrm{P}$ latelet activation is a key feature of acute coronary syndromes $(\mathrm{ACS})^{1}$ and also occurs after percutaneous coronary intervention (PCI), in particular when a stent is placed. ${ }^{2}$ Periprocedural use of platelet glycoprotein (Gp) IIb/ IIIa $\left(\alpha_{\text {IIb }} \beta_{\text {IIII }}\right)$ receptor (Gp IIb/IIIa) blockers has been shown to reduce the risk of major adverse cardiac events (death, myocardial infarction, and repeat revascularisation) after PCI with or without coronary stenting. ${ }^{3}$ Use of Gp IIb/IIIa blockers has also been shown to reduce event rates in patients with ACS. ${ }^{5-8}$ Furthermore, combined use of Gp IIb/ IIIa antagonists and low dose heparin reduces the risk of ischaemic complications, without increasing the risk of haemorrhage.

Long term restenosis of the dilated segment of a coronary artery remains a problem and occurs in up to $30 \%$ of patients after PCI even with the use of stents. ${ }^{9}{ }^{10}$ Greater activation of inflammatory processes after PCI predicts restenosis, perhaps by stimulating smooth muscle cell proliferation. ${ }^{11}{ }^{12}$ Restenosis results from a combination of smooth muscle proliferation, recoil, and incorporation of thrombus ${ }^{913}{ }^{14}$ and has remained a problem despite the use of Gp IIb/IIIa receptor blockers. ${ }^{3}$ Persistent platelet activation, despite the abrogation of aggregation by the Gp IIb/IIIa blockers, may play a key part through the generation of platelet-leucocyte conjugates, increased leucocyte activation, and release of inflammatory mediators and growth factors. ${ }^{11}{ }^{15} 16$ P selectin, an adhesion molecule, acts as a marker for activated platelets, which contribute to leucocyte conjugate formation by binding P selectin glycoprotein ligand (PSGL)-1. ${ }^{17}$

At present, before PCI, a bolus of unfractionated heparin (UFH) is given, with or without additional Gp IIb/IIIa blockade. The main limitation of UFH results from its propensity to bind to positively charged proteins and surfaces. Pharmacokinetic limitations are caused by binding of UFH to plasma proteins, platelet proteins, and endothelial cells, resulting in a variable anticoagulant response and the phenomenon of heparin resistance. Although an exact therapeutic dose of low molecular weight heparin (LMWH) required for PCI is still unknown, it has been suggested as an alternative, since it has a predictable dose response, eliminating the need for assessments of coagulation. In addition, the risk of heparin induced thrombocytopenia is lower with LMWH. ${ }^{18}$ Data from treatment of ACS suggest benefit in using LMWH rather than UFH. ${ }^{19}{ }^{20}$ Therefore, it has been suggested that use of LMWH in preference to UFH in PCI may be beneficial even though randomised controlled comparisons are not yet available.

The two main thrombin receptors on human platelets are protease activated receptor (PAR)- $1^{21}$ and platelet Gp Ib. ${ }^{22}$ These receptors act synergistically in the platelet response to thrombin through a necessary cofactor role for $\mathrm{Gp} \mathrm{Ib}$ during PAR-1 activation. ${ }^{23}$ Activation of Gp Ib by thrombin, in turn, is inhibited by heparin and this is directly proportional to the chain length of the oligosaccharide. ${ }^{24}$ The possibility, therefore, exists that heparin may provide additional protection beyond anticoagulation in PCI by inhibiting platelet activation and that protection is related to the molecular weight of the molecule.

To understand better the relative merits of using combinations of Gp IIb/IIIa antagonists with UFH and LMWH to

\footnotetext{
Abbreviations: ACS, acute coronary syndromes; ELISA, enzyme linked immunosorbent assay; ESSENCE, efficacy and safety of subcutaneous enoxaparin in non-Q wave coronary events; Gp, glycoprotein; LMWH, low molecular weight heparin; PAR, protease activated receptor; $\mathrm{PCl}$, percutaneous coronary intervention; PDGF, platelet derived growth factor; POLONIA, Polish-American local Lovenox NIR assessment; PSGL, $P$ selectin glycoprotein ligand; SYNERGY, superior yield of the new strategy of enoxaparin, revascularisation and glycoprotein Illb/lla inhibitors; TRAP, thrombin receptor activating peptide; UFH, unfractionated heparin
} 
control platelet function, we have analysed platelet activation and aggregation in vitro. Our results confirm that heparin provides protection from thrombin induced platelet activation not afforded by Gp IIb/IIIa antagonists and in addition that UFH may be significantly better in this respect than LMWH.

\section{METHODS}

\section{Reagents and antibodies}

Collagen, thrombin, and ADP were obtained from Sigma Diagnostics (Poole, UK). Adrenaline was obtained from Helena Biosciences (Sunderland, UK). The PAR-1 agonist hexapeptide SFLLRN (thrombin receptor activating peptide (TRAP)-6) was synthesised by the Advanced Biotechnology Centre (Imperial College School of Medicine, London, UK). Abciximab (ReoPro) was obtained from Centocor BV (Leiden, the Netherlands), tirofiban (Aggrastat) from Merck Pharmaceuticals (Middlesex, UK), eptifibatide (Integrilin) from Millennium Pharmaceuticals (Cambridge, UK), enoxaparin (Clexane) from Rhône-Poulenc Rorer (Kent, UK), and UFH sodium (Monoparin) from CP Pharmaceuticals Ltd (Wrexham, UK). Phycoerythrin conjugated monoclonal mouse anti-human CD62P P selectin and mouse $\mathrm{IgG}_{1}$ negative control antibodies were purchased from Dako A/S (Ely, UK). The enzyme linked immunosorbent assay (ELISA) kit for platelet derived growth factor (PDGF)-AB was purchased from R\&D Systems (Abingdon, UK).

\section{Platelet preparation}

Washed platelets were prepared from peripheral blood samples of normal healthy human volunteers, as previously described. ${ }^{25}$ Absence of clotting factors was shown by lack of detectable antithrombin III $(<0.01 \mathrm{U} / \mathrm{ml})$, protein $\mathrm{C}$ $(<0.01 \mathrm{U} / \mathrm{ml})$, and protein $\mathrm{S}(<0.01 \mathrm{U} / \mathrm{ml})$ in the platelet suspension.

\section{Platelet aggregation}

Platelet aggregation was studied with the use of an APACT 4 platelet aggregometer (Helena Biosciences). Platelet agonists such as thrombin $(3 \mathrm{nmol} / \mathrm{l})$, TRAP-6 $(50 \mu \mathrm{mol} / \mathrm{l})$, adrenaline $(10 \mu \mathrm{g} / \mathrm{ml})$, collagen $(50-100 \mu \mathrm{g} / \mathrm{ml})$, and ADP $(4 \mu \mathrm{mol} / \mathrm{l})$ were added to $200 \mu \mathrm{l}$ aliquots of platelet solution $\left(200 \times 10^{9}-\right.$ $\left.400 \times 10^{9} / 1\right)$, as previously described, ${ }^{25}$ with combinations of abciximab $(3.5 \mu \mathrm{g} / \mathrm{ml})$, tirofiban $(0.25 \mu \mathrm{g} / \mathrm{ml})$, or eptifibatide $(2.5 \mu \mathrm{g} / \mathrm{ml})$ and LMWH $(0.25 \mathrm{U} / \mathrm{ml})$ or UFH $(0.25 \mathrm{U} / \mathrm{ml})$. The concentrations of UFH (mean molecular weight $15000 \mathrm{Da}$ ) and LMWH (mean molecular weight 4500-5000 Da) were based on reported therapeutic plasma concentrations ${ }^{26}$ and those of Gp IIb/IIIa inhibitors on the clinical doses used in a $70 \mathrm{~kg}$ patient with a circulating volume of $5 \mathrm{l}$.

\section{Flow cytometric analysis}

Platelets were washed and aggregation was initiated by agonists as described above. At fixed time points, based on the aggregation parameters (thrombin 180 seconds, collagen 300 seconds, ADP 180 seconds, adrenaline (epinephrine) 300 seconds) the platelets were fixed with $1 \%$ paraformaldehyde, washed with phosphate buffer solution, and centrifuged at $3000 \mathrm{rpm}$. The pellets were resuspended and incubated for 30 minutes with $20 \mu \mathrm{g} / \mathrm{ml}$ of either phycoerythrin conjugated monoclonal mouse anti-human $\mathrm{P}$ selectin (CD62P) antibody or phycoerythrin conjugated mouse $\operatorname{IgG}_{1}$ negative control antibody. The platelets were washed again, centrifuged at $3000 \mathrm{rpm}$, and resuspended in $1 \mathrm{ml}$ of phosphate buffer solution. P selectin expression was analysed with a Beckman Coulter XL flow cytometer (High Wycombe, UK) on the gated platelet population. $\mathrm{P}$ selectin was expressed as relative fluorescence intensity, which was obtained by dividing the mean fluorescence intensity obtained with phycoerythrin conjugated CD62P antibody by that obtained with phycoerythrin conjugated control antibody.

\section{Intraplatelet calcium concentrations}

Platelets were loaded with Fura-2 AM (Molecular probes Inc, Eugene, Oregon, USA) for 45 minutes at $37^{\circ} \mathrm{C}$, as previously described. ${ }^{25}$ Intracellular calcium was measured by measuring the Fura-2 fluorescence at $340 \mathrm{~nm}$ excitation and $510 \mathrm{~nm}$ emission with an LS 50 B spectrofluorometer (Perkin Elmer, Beaconsfield, UK). Platelets prepared with UFH $(0.2 \mathrm{U} / \mathrm{ml})$ or abciximab $(2 \mu \mathrm{g} / \mathrm{ml})$ were added until a steady baseline reading was obtained. Platelet agonists were then added at the same concentrations as those used in aggregometry, after which fluorescence tracings were obtained. Intraplatelet calcium fluxes were determined by subtracting the baseline concentration from peak concentrations and calibrating to a known standard.

\section{Statistical analysis}

Treatment groups in CD62P, PDGF, and monocyte chemoattractant protein 1 experiments were compared by a two tailed Student's $t$ test. Significance was assumed at $\mathrm{p}<0.05$.

\section{RESULTS}

\section{Selective versus broad based inhibition of platelet aggregation by heparin and Gp IIb/IIla inhibitors, respectively}

As expected, we showed that platelet aggregation caused by thrombin, adrenaline, collagen, or ADP was inhibited by abciximab through blockade of the Gp IIb/IIIa receptor (fig 1). Similar results were obtained with eptifibatide and tirofiban (data not shown). In contrast, UFH and LMWH inhibited aggregation caused by thrombin (fig lA) but not caused by adrenaline (fig 1B), collagen (fig 1C), or ADP (fig lD). To confirm that heparin was acting on the afferent arm of the thrombin activation pathway, we showed that transduction of intraplatelet activating signals, as measured by calcium flux, was inhibited by UFH (fig 2A). In contrast, when the thrombin receptor PAR-1 was activated directly by TRAP-6, which bypasses the need for cofactoring with $\mathrm{Gp} \mathrm{Ib}{ }^{23} \mathrm{UFH}$ and LMWH had no effect on calcium flux (fig 2B) or platelet aggregation (fig 2C). This was therefore consistent with heparin inhibiting the thrombin induced platelet activation by blocking the platelet $\mathrm{Gp}$ Ib receptor. ${ }^{24}$

\section{Selective inhibition of platelet activation by heparin but not Gp IIb/IIla blockers}

To examine downstream consequences of platelet activation, we investigated P selectin (CD62P) expression and release of PDGF from activated platelets. Using P selectin expression as a marker of platelet activation, we showed that thrombin caused platelet activation and that this was significantly inhibited by LMWH $(p=0.0183)$ and UFH $(p<0.001)$ (fig 3A). Furthermore, UFH was significantly better than LMWH $(\mathrm{p}=0.0014)$ at blocking P selectin expression. None of the Gp IIb/IIIa antagonists significantly inhibited P selectin expression caused by thrombin, nor did they act synergistically when combined with LMWH or UFH (fig 3B, C, D). An analogous picture was observed in the case of PDGF release by platelets. Here also, thrombin caused PDGF release and this was significantly inhibited by LMWH $(\mathrm{p}=0.0300)$ and UFH ( $p=0.0121$ ) (fig 4A). Similarly, none of the Gp IIb/IIIa blockers significantly inhibited PDGF release and there was no additive effect when combined with LMWH or UFH (fig 4B, C, D). Taken together, these results show that UFH and $\mathrm{LMWH}$ protect platelets from activation by thrombin but that the Gp IIb/IIIa antagonists abciximab, eptifibatide, and tirofiban do not. 
A

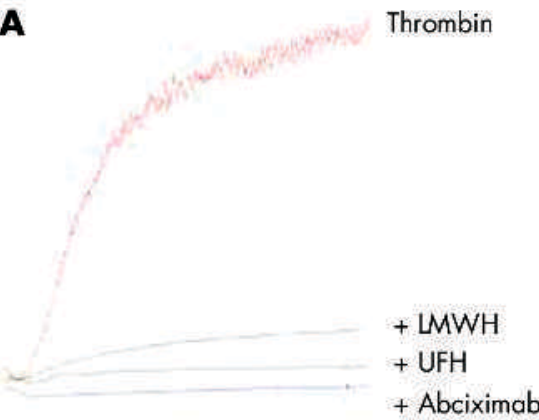

B

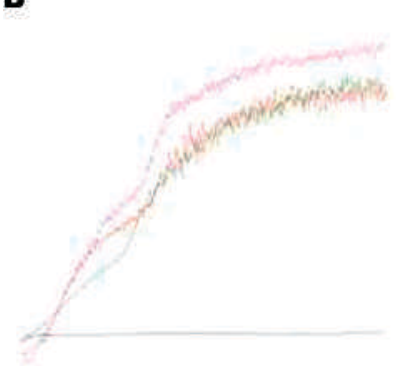

Adrenaline

+ LMWH

$+\mathrm{UFH}$

+ Abciximab
C

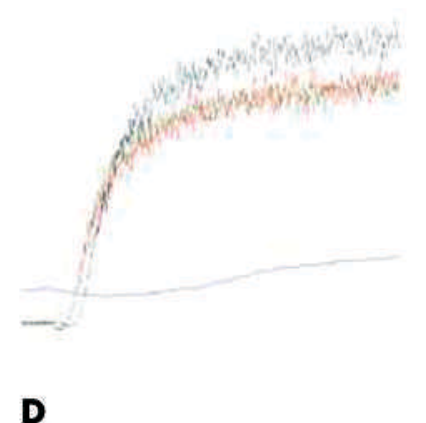

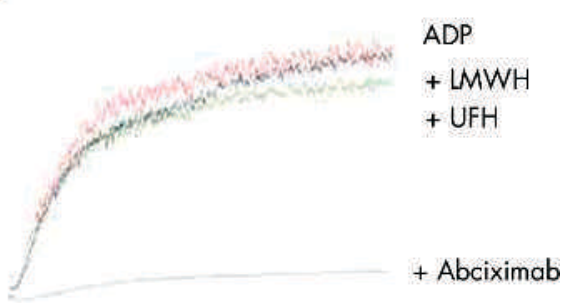

Figure 1 Platelet aggregometry traces showing effects of clinically relevant concentrations unfractionated heparin (UFH), low molecular weight heparin (LMWH), and abciximab on platelet aggregation induced by $(A)$ thrombin, (B) adrenaline, (C) collagen, and (D) ADP. Washed platelets $\left(4 \times 10^{7}-8 \times 10^{7}\right)$ were

+ Abciximab preincubated with UFH, LMWH, or abciximab for five minutes before addition of agonist. Aggregation was carried out for 300 seconds. Traces are representative of 10 similar experiments.

\section{DISCUSSION}

Prevention of thrombin induced platelet activation reduces acute complications after PCI. UFH and LMWH inhibit thrombin induced platelet activation, as judged by platelet aggregation, P selectin expression, and PDGF release. However, heparin is effective only when thrombin is the agonist. In contrast, Gp IIb/IIIa inhibitors block aggregation caused by all platelet agonists but have no effect on P selectin expression or PDGF release. The actions of heparin and Gp

A

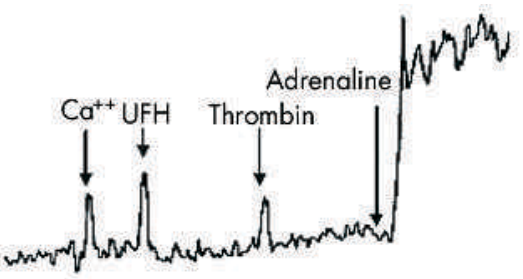

B

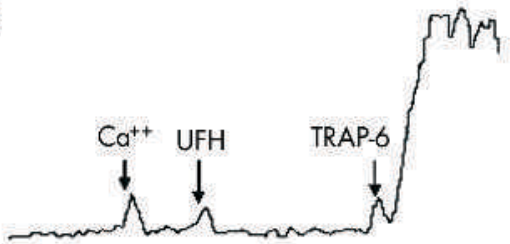

C

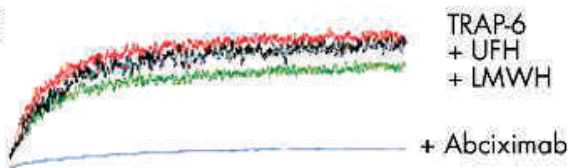

Figure 2 (A) UFH inhibited thrombin but not adrenaline induced platelet calcium fluxes. (B) UFH did not affect thrombin receptor activating peptide (TRAP)- 6 induced calcium fluxes. (C) Abciximab, but not UFH or LMWH, inhibited TRAP-6 induced platelet aggregation. Washed platelets $\left(4 \times 10^{7}-8 \times 10^{7}\right)$ were preincubated with UFH, $\mathrm{LMWH}$, or abciximab for five minutes before addition of agonist. Aggregation was carried out for 300 seconds. Traces are representative of 10 similar experiments. Panels (A) and (B) show representative fluorimetry traces indicating calcium influx on an arbitrary scale based on Fura-2 loaded platelets $\left(4 \times 10^{7}-8 \times 10^{7}\right)$. Calcium flux was read over 300 seconds. Traces are representative of five similar experiments.
IIb/IIIa antagonists are, therefore, complementary. In addition, we have found that complete inhibition of platelet activation was afforded only by UFH.

The use of Gp IIb/IIIa blockers in ACS and during PCI is validated by clinical trial data. ${ }^{5-8}$ The clinical benefits of LMWH over UFH have been established in patients with ACS but not in PCI. ${ }^{19} 20$ This has not stopped suggestions that LMWH pharmacotherapy in PCI may be as safe and effective as UFH. ${ }^{27-29}$ The present study, however, suggests that UFH is more effective than $\mathrm{LMWH}$ in inhibiting platelet activation caused by thrombin.

Persistent platelet activation, despite the abrogation of aggregation by the Gp IIb/IIIa blockers, may play a key part in restenosis after PCI through the generation of plateletleucocyte conjugates, increased leucocyte activation, and the release of inflammatory mediators and growth factors. ${ }^{11} 1516$ Platelet-leucocyte conjugates are increased in ACS and this has been shown to be due to the molecular interaction between increased $\mathrm{P}$ selectin on platelets and PSGL-1 expressed by leucocytes. ${ }^{17}{ }^{30}$ Thrombin activated platelets use the $\mathrm{P}$ selectin/PSGL-1 adhesion pathway to stimulate conjoined monocytes, thus leading to secretion of the proinflammatory cytokines interleukin $1 \beta$, interleukin 8 , and monocyte chemoattractant protein $1 .{ }^{3132} \mathrm{P}$ selectin also induces tissue factor expression and fibrin deposition by monocytes, thus contributing to the evolution of the thrombus. $^{33}{ }^{34}$ Since UFH exhibited substantially greater inhibition of $\mathrm{P}$ selectin expression than LMWH, this may translate into decreased inflammation and thrombus formation and ultimately lower restenosis rates, ${ }^{15}$ if UFH is used rather than LMWH during PCI. Gp Ib binding by thrombin is inhibited by heparin and the extent of inhibition was directly related to the oligosaccharide chain length. ${ }^{24}$ Since under normal conditions PAR-1 and Gp Ib act synergistically in the platelet response to thrombin, ${ }^{23}$ this may explain why UFH is more effective than $\mathrm{LMWH}$ at blocking platelet activation.

Three small trials have compared LMWH with UFH during PCI without Gp IIb/IIIa blockers. ${ }^{35-37}$ Although the POLONIA (Polish-American local Lovenox NIR assessment) study suggested a possible reduction in restenosis with local delivery of enoxaparin before PCI, these results have yet to be confirmed. ${ }^{37}$ Data from the ESSENCE (efficacy and safety 

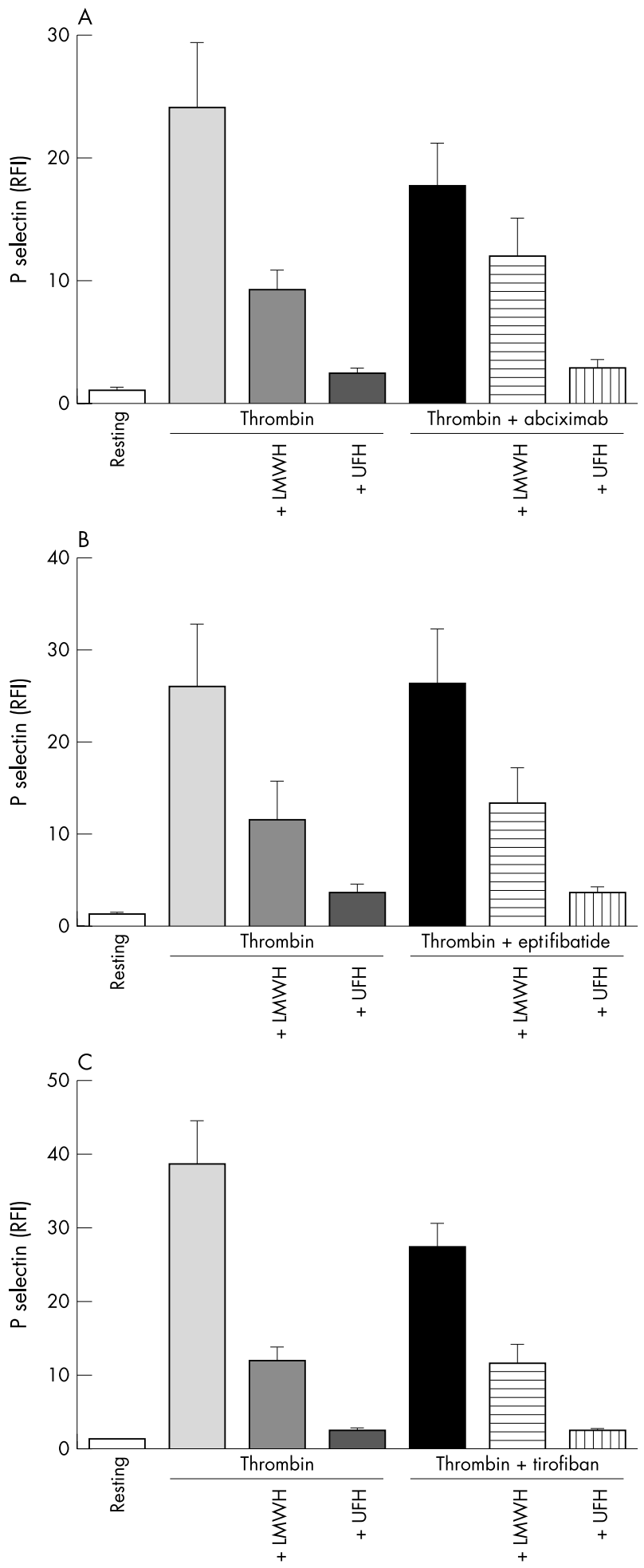

Figure 3 Effect of (A) abciximab, (B) eptifibatide, and (C) tirofiban in combination with UFH or LMWH on thrombin induced $\mathrm{P}$ selectin expression. Platelets were prepared as described for aggregation. Platelet activation was halted at 180 or 300 seconds by the addition of paraformaldehyde before staining with anti-P selectin (CD62P) and flow cytometric analysis. Results are depicted as the mean (SEM) relative fluorescent intensity (RFI) from eight experiments.

of subcutaneous enoxaparin in non-Q wave coronary events) trial (comparing LMWH with UFH for ACS) suggests that PCI can be safely performed while the patient is given LMWH. However, only $13 \%$ of patients underwent PCI and these
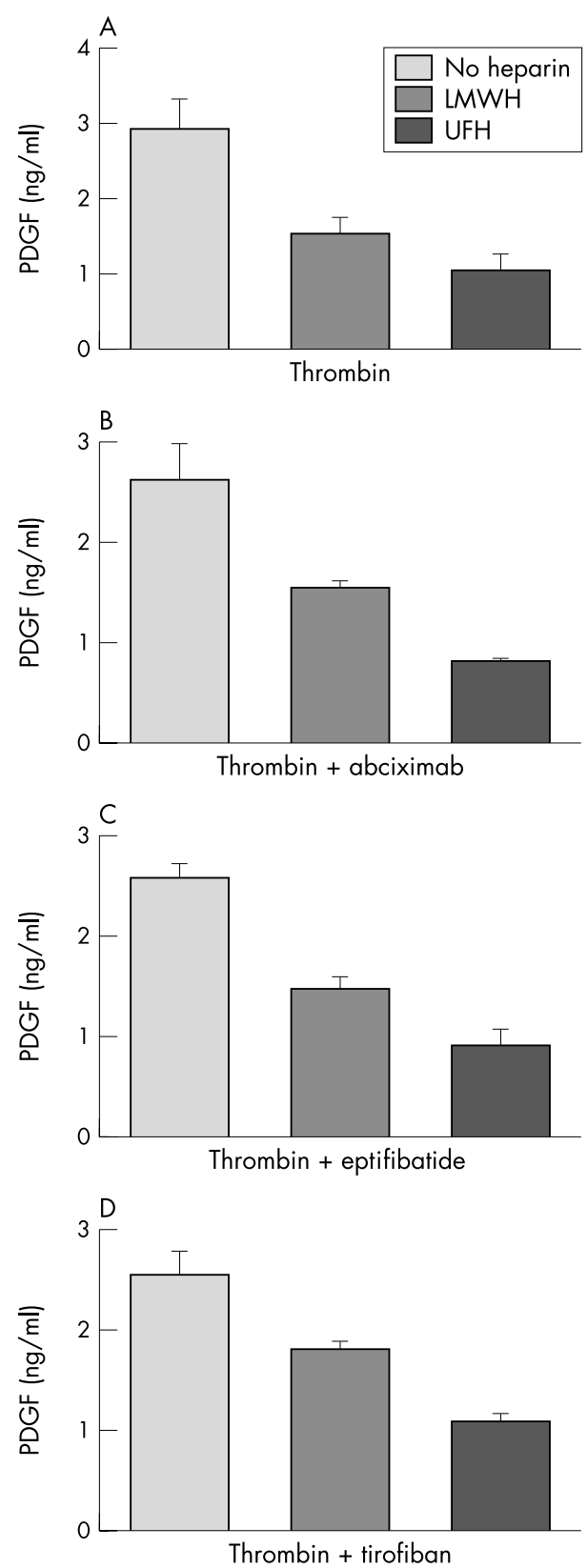

Figure 4 Effect of (A) thrombin, (B) thrombin + abciximab, (C) thrombin + eptifibatide, and (D) thrombin + tirofiban in combination with UFH or LMWH on platelet derived growth factor (PDGF) release. Supernatants were collected from aggregated platelets and PDGF concentrations were determined by enzyme linked immunosorbent assay (ELISA). Supernatants were assayed in quadruplicate. Results are mean (SEM) from two experiments.

patients were not randomly assigned to UFH or $\mathrm{LMWH}^{27}$ In addition, 56 of the 445 patients given LMWH got extra UFH during the PCI.

Initial safety studies attest to the ability of Gp IIb/IIIa blockers plus LMWH to stop acute thrombosis after PCI. ${ }^{38} 39$ However, no longer term data are available to assess the effect on restenosis. The A-Z trial is assessing the impact of enoxaparin versus UFH in patients with ACS who are already taking tirofiban. $^{40}$ Although the comparison will not be randomised, the majority of patients in the trial are likely to undergo intervention and it may be possible to compare UFH groups with LMWH groups. More direct data will be available 
from the SYNERGY (superior yield of the new strategy of enoxaparin, revascularisation and glycoprotein IIb/IIIa inhibitors) trial, in which patients taking Gp IIb/IIIa blocker will be randomly assigned to the use of either enoxaparin or UFH during PCI. ${ }^{41}$ Our data provide a framework through which the results of clinical trials may be explained.

We have taken forward early studies ${ }^{23}{ }^{24}$ by examining thrombin induced platelet activation based on clinically relevant markers such as $\mathrm{P}$ selectin expression and PDGF release and by using clinical concentrations of commercially available heparin and Gp IIb/IIIa inhibitors. We have also confirmed by using TRAP-6 that the likely mechanism of platelet protection is through inhibition of Gp Ib. Our study was undertaken in vitro and the effects shown may not translate into an in vivo effect on restenosis. However, in the absence of any relevant clinical trials, the in vitro approach is useful in assessing mechanisms of action. Although Xiao and colleagues ${ }^{26}$ have shown that UFH activates resting platelets, the level of activation is insignificant when compared with that caused by thrombin. We have not addressed the combined use of heparin with oral antiplatelet agents such as aspirin and clopidogrel that are used clinically during ACS and PCI. Clopidogrel inhibits platelet aggregation in response to ADP and this may be of additional benefit. ${ }^{42}$

\section{Conclusion}

The present investigation suggests that UFH and LMWH exert complementary effects when coadministered with Gp IIb/IIIa blockers. By inhibiting the afferent arm of thrombin induced platelet activation heparin may provide additional protection beyond anticoagulation in PCI. UFH may be more effective in this regard than LMWH, at least in vitro. Restenosis after PCI may, in part, be caused by smooth muscle cell proliferation related to platelet activation. The use of LMWH in preference to UFH during PCI, although superficially attractive, may inadequately protect against platelet activation despite the presence of Gp IIb/IIIa blockers.

\section{ACKNOWLEDGEMENTS}

This work was supported by The British Heart Foundation.

\section{Authors' affiliations}

J R S Day*, A Weerasinghe, M Poullis, K M Taylor, British Heart Foundation Cardiac Surgery Unit, The Hammersmith Hospital, London, UK

I S Malik*, Waller Department of Cardiology, St Mary's Hospital, London, UK

I Nadra, D O Haskard, R C Landis, Cardiovascular Medicine Unit, The Hammersmith Hospital

*These authors contributed equally to the work

\section{REFERENCES}

1 Ault KA, Cannon CP, Mitchell J, et al. Platelet activation in patients after an acute coronary syndrome: results from the TIMI-12 trial. Thrombolysis in myocardial infarction. J Am Coll Cardiol 1999;33:634-9.

2 Gawaz M, Neumann FJ, OH I, et al. Changes in membrane glycoproteins of circulating platelets after coronary stent implantation. Heart 1996;76:166-72.

3 EPISTENT Investigators. Randomised placebo-controlled and balloonangioplasty-controlled trial to assess safety of coronary stenting with use of platelet glycoprotein-llb/Illa blockade. The EPISTENT Investigators. Evaluation of platelet Ilb/Illa inhibitor for stenting. Lancet 1998;352:87-92.

4 EPIC Investigators. Use of a monoclonal antibody directed against the platelet glycoprotein Ilb/llla receptor in high-risk coronary angioplasty. The EPIC investigation. N Engl J Med 1994;330:956-61.

5 PRISM-PLUS Investigators. Inhibition of the platelet glycoprotein IIb/IIla receptor with tirofiban in unstable angina and non-Q-wave myocardial infarction. Platelet receptor inhibition in ischemic syndrome management in patients limited by unstable signs and symptoms (PRISM-PLUS) study investigators. N Engl J Med 1998;338:1488-97.

6 PRISM Investigators. A comparison of aspirin plus tirofiban with aspirin plus heparin for unstable angina. Platelet receptor inhibition in ischemic syndrome management (PRISM) study investigators. N Engl J Med 1998;338:1498-505.

7 CAPTURE Investigators. Randomised placebo-controlled trial of abciximab before and during coronary intervention in refractory unstable angina: the CAPTURE Study. Lancet 1997;349:1429-35.

8 PURSUIT Investigators. Inhibition of platelet glycoprotein Illb/llla with eptifibatide in patients with acute coronary syndromes. The PURSUIT Trial Investigators. Platelet glycoprotein Ilb/lla in unstable angina: receptor suppression using integrilin therapy. N Engl J Med 1998;339:436-43.

9 Califf RM, Fortin DF, Frid DJ, et al. Restenosis after coronary angioplasty: an overview. J Am Coll Cardiol 1991; 17(6 suppl B):2B-13B.

10 Van Belle E, Bauters C, Hubert E, et al. Restenosis rates in diabetic patients: a comparison of coronary stenting and balloon angioplasty in native coronary vessels. Circulation 1997:96:1454-60.

11 Serrano CV Jr, Ramires JA, Venturinelli M, et al. Coronary angioplasty results in leukocyte and platelet activation with adhesion molecule expression: evidence of inflammatory responses in coronary angioplasty. J Am Coll Cardiol 1997;29:1276-83.

12 Gottsauner-Wolf $M$, Zasmeta G, Hornykewycz S, et al. Plasma levels of C-reactive protein after coronary stent implantation. Eur Heart $J$ 2000;21:1152-8

13 Anderson HV, Vignale SJ, Benedict CR, et al. Restenosis after coronary angioplasty. J Interv Cardiol 1993:6:187-202.

14 Austin GE, Ratliff NB, Hollman J, et al. Intimal proliferation of smooth muscle cells as an explanation for recurrent coronary artery stenosis after percutaneous transluminal coronary angioplasty. J Am Coll Cardiol 1985;6:369-75.

15 Ishiwata S, Tukada T, Nakanishi S, et al. Postangioplasty restenosis: platelet activation and the coagulation-fibrinolysis system as possible factors in the pathogenesis of restenosis. Am Heart J 1997;133:387-92.

16 Mickelson JK, Lakkis NM, Villarreal-Levy G, et al. Leukocyte activation with platelet adhesion after coronary angioplasty: a mechanism for recurrent disease? J Am Coll Cardiol 1996:28:345-53.

17 Larsen E, Celi A, Gilbert GE, et al. PADGEM protein: a receptor that mediates the interaction of activated platelets with neutrophils and monocytes. Cell 1989;59:305-12.

18 Warkentin TE, Levine MN, Hirsh J, et al. Heparin-induced thrombocytopenia in patients treated with low-molecular-weight heparin or unfractionated heparin. N Engl J Med 1995;332:1330-5.

19 Goodman SG, Cohen M, Bigonzi F, et al. Randomized trial of low molecular weight heparin (enoxaparin) versus unfractionated heparin for unstable coronary artery disease: one-year results of the ESSENCE study. Efficacy and safety of subcutaneous enoxaparin in non-Q wave coronary events. J Am Coll Cardiol 2000;36:693-8

20 FRISC II Investigators. Long-term low-molecular-mass heparin in unstable coronary-artery disease: FRISC II prospective randomised multicentre study. Fragmin and fast revascularisation during instability in coronary artery disease investigators. Lancet 1999;354:701-7.

21 Vu TK, Hung DT, Wheaton VI, et al. Molecular cloning of a functional thrombin receptor reveals a novel proteolytic mechanism of receptor activation. Cell 1991;64:1057-68.

22 De Marco L, Mazzucato M, Masotti A, et al. Function of glycoprotein lb alpha in platelet activation induced by alpha-thrombin. J Biol Chem 1991;266:23776-83.

23 De Candia E, Hall SW, Rutella S, et al. Binding of thrombin to glycoprotein lb accelerates the hydrolysis of Par-1 on intact platelets. J Biol Chem 2001;276:4692-8.

24 De Candia E, De Cristofaro R, Landolfi R. Thrombin-induced platelet activation is inhibited by high- and low-molecular-weight heparin. Circulation 1999:99:3308-14.

25 Poullis $M$, Manning R, Laffan $M$, et al. The antithrombotic effect of aprotinin: actions mediated via the protease activated receptor 1. J Thorac Cardiovasc Surg 2000;120:370-8.

26 Xiao Z, Theroux P. Platelet activation with unfractionated heparin at therapeutic concentrations and comparisons with a low-molecular-weight heparin and with a direct thrombin inhibitor. Circulation 1998;97:251-6.

27 Fox KA, Antman EM, Cohen $M$, et al. Comparison of enoxaparin versus unfractionated heparin in patients with unstable angina pectoris/non-STsegment elevation acute myocardial infarction having subsequent percutaneous coronary intervention. Am J Cardiol 2002;90:477-82.

28 Arjomand H, Surabhi SK, Cohen M. Unfractionated versus fractionated heparin for percutaneous coronary intervention. Curr Cardiol Rep 2002;4:327-33.

29 Furman MI, Kereiakes DJ, Krueger LA, et al. Leukocyte-platelet aggregation, platelet surface P-selectin, and platelet surface glycoprotein Illa after percutaneous coronary intervention: effects of dalteparin or unfractionated heparin in combination with abciximab. Am Heart J 2001;142:790-8.

30 Sarma J, Laan CA, Alam S, et al. Increased platelet binding to circulating monocytes in acute coronary syndromes. Circulation 2002;105:2166-71.

31 Weyrich AS, Elstad MR, McEver RP, et al. Activated platelets signal chemokine synthesis by human monocytes. J Clin Invest 1996;97:1525-34.

32 Neumann FJ, Hochholzer W, Pogatsa-Murray G, et al. Antiplatelet effects of abciximab, tirofiban and eptifibatide in patients undergoing coronary stenting. J Am Coll Cardiol 2001;37:1323-8.

33 Celi A, Pellegrini G, Lorenzet R, et al. P-selectin induces the expression of tissue factor on monocytes. Proc Natl Acad Sci U S A 1994;91:8767-71.

34 Palabrica T, Lobb R, Furie BC, et al. Leukocyte accumulation promoting fibrin deposition is mediated in vivo by P-selectin on adherent platelets. Nature 1992;359:848-51

35 Karsch KR, Preisack MB, Baildon R, et al. Low molecular weight heparin (reviparin) in percutaneous transluminal coronary angioplasty: results of a 
randomized, double-blind, unfractionated heparin and placebo-controlled, multicenter trial (REDUCE trial). Reduction of restenosis after PTCA, early administration of reviparin in a double-blind unfractionated heparin and placebo-controlled evaluation. J Am Coll Cardiol 1996;28:1437-43.

36 Rabah MM, Premmereur J, Graham M, et al. Usefulness of intravenous enoxaparin for percutaneous coronary intervention in stable angina pectoris. Am J Cardiol 1999;84:1391-5.

37 Kiesz RS, Buszman P, Martin JL, et al. Local delivery of enoxaparin to decrease restenosis after stenting: results of initial multicenter trial: PolishAmerican local Lovenox NIR assessment study (the POLONIA study). Circulation 2001;103:26-31.

38 Kereiakes DJ, Grines C, Fry E, et al. Enoxaparin and abciximab adjunctive pharmacotherapy during percutaneous coronary intervention. J Invasive Cardiol $2001 ; 13: 272-8$.
39 Kereiakes DJ, Kleiman NS, Fry E, et al. Dalteparin in combination with abciximab during percutaneous coronary intervention. Am Heart $J$ $2001 ; 141: 348-52$

40 Blazing MA, De Lemos JA, Dyke CK, et al. The A-to-Z trial: methods and rationale for a single trial investigating combined use of low-molecular-weight heparin with the glycoprotein Ilb/Illa inhibitor tirofiban and defining the efficacy of early aggressive simvastatin therapy. Am Heart J 2001;142:211-7.

41 SYNERGY Investigators. The SYNERGY trial: study design and rationale. Am Heart J 2002;143:952-60.

42 Gachet C, Stierle A, Cazenave JP, et al. The thienopyridine PCR 4099 selectively inhibits ADP-induced platelet aggregation and fibrinogen binding without modifying the membrane glycoprotein Ilb-Illa complex in rat and in man. Biochem Pharmacol 1990:40:229-38.

\section{IMAGES IN CARDIOLOGY}

\section{Successful stenting of the left anterior descending artery in a patient with a single left coronary ostium}

\begin{abstract}
A
51 year old patient presented with an acute anterior myocardial infarction and had reperfusion therapy with thrombolysis. Electrocardiograms post-thrombolysis showed complete resolution of ST segment elevation with normal creatine kinase values and troponin $\mathrm{T}$ concentration of $0.02 \mu \mathrm{g} / \mathrm{l}$. Because of post-infarct unstable angina the patient underwent cardiac catheterisation. This showed normal left ventricular function with a single left coronary ostium. The left main stem was normal. The left anterior descending artery (LAD) had two severe subtotal occlusions in the proximal and mid thirds (below left, black arrows). Arising from between these two stenoses was the right coronary artery (RCA) which was non-dominant and diseased with atheroma (white arrow). The left circumflex was normal and dominant. Percutaneous coronary intervention (PCI) was undertaken with stenting to the LAD artery. The final angiographic result was excellent with the RCA
\end{abstract}

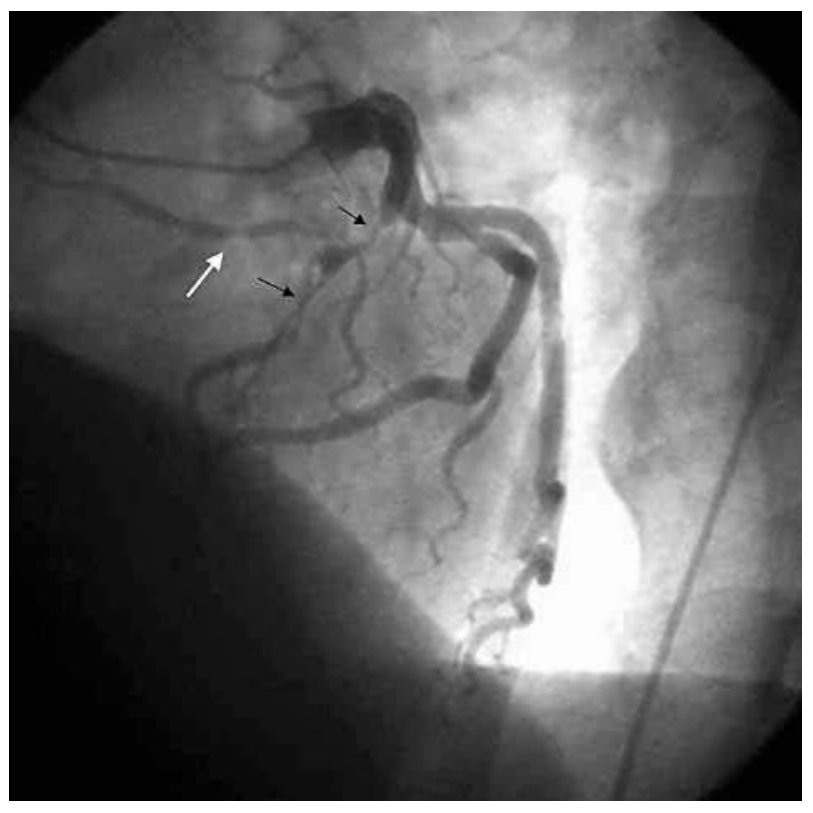

remaining patent and exiting the stented region of the LAD (below right)

An isolated single coronary ostium is a rare coronary anomaly occurring in $0.024-0.04 \%$ of the population. When a single coronary ostium arises from the left sinus of Valsalva, the anomalous RCA usually arises from the LAD artery. Other sites of origin are the circumflex artery, pulmonary trunk, aorta or extra cardiac arteries such as the internal mammary or subclavian arteries. PCI through a single coronary ostium is technically possible. These patients are at a higher risk of ischaemic complications as the single coronary ostium is the myocardium's sole supply of blood.

S Aziz

D R Ramsdale saziz1@btinternet.com

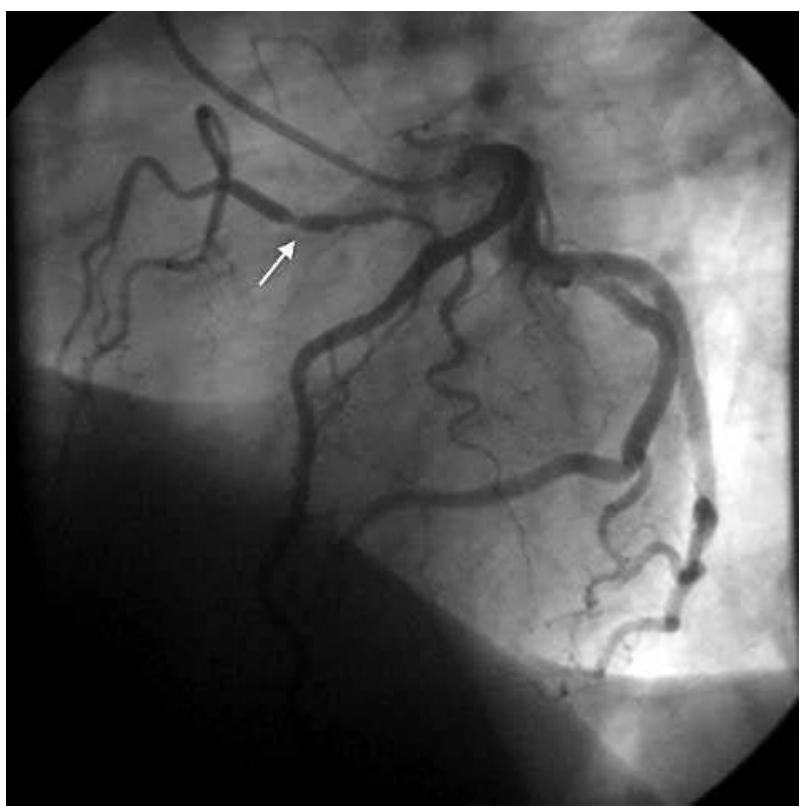

